\title{
Attraction to Conspecific and Nonconspecific Chemical Stimuli in Male and Female Macropodus opercularis (Teleostei, Anabantoidei) ${ }^{1,2}$
}

\author{
ROGER E. DAVIS and NANCY J. PILOTTE \\ Neurosciences Laboratory, Mental Health Research Institute, \\ and the Department of Psychology, University of Michigan \\ Ann Arbor, Michigan 48104
}

\begin{abstract}
Socially isolated Macropodus opercularis showed a distinct approach response to water taken from the tank of a conspecific individual or a nonconspecific, Trichogaster trichopterus, but not to water from a tank without fish. It is proposed that these species produce chemical stimuli which are attractive to $M$. opercularis. Approach frequency and the total duration of approach during a 10-min period of stimulation varied with the species and the sex of the stimulus fish but not with the sex of the subject. Subjects responded most frequently to the conspecific male and nonconspecific female stimuli and, least to the nonconspecific male stimuli.
\end{abstract}

Rossi (1969) reported that solitary male Macropodus opercularis (family, Belontiidae; subfamily, Macropodinae) show increased nest building and aggressivity in response to female chemical stimuli. Observations in this laboratory during various experiments on social behavior (Davis, Harris, and Shelby, 1974) confirm that mature $M$. opercularis respond to chemical cues from species mates. Water that has contained a female for a period of days can elicit immediate arousal consisting of erection of the medial fins and striking changes in skin color in an isolated male. These are elements of the species-typical responses which are seen in courtship and nest defense (Forselius, 1957; Ward, 1967). In addition, in a situation in which female stimulus water is" added slowly through a tube at the water surface, fish approach the incurrent tube and investigate the opening. The approach response occurs even when the behavioral arousal response does not, as when the stimulus is diluted with fresh water prior to entering the tank.

1 We thank Jessie Shelby for her valuable technical assistance.

2Liem's classification of the order Anabantoidei into four families is preferred because it presents a more convincing hypothesis of the natural relationships between the divergent species in this group than does the older classification of Regan (1906). 
The purpose of the present experiment was to determine whether the frequency and duration of the approach response to chemical stimuli varies with the sex of the subject and of the stimulus fish. Based on Rossi's (1969) report and preliminary observations in this laboratory it was anticipated that males would show a greater tendency to approach female than male stimuli, and females would respond less intensively than males. An additional aim was to find out whether $M$. opercularis responds differently to stimuli from species mates than to stimuli from another species, Trichogaster trichopterus. $T$. Trichopterus is a belontid teleost of the subfamily Trichogasterinae. It was selected as a nonconspecific stimulus because of its close phylogenetic relation to $M$. opercularis and because previous experiments (Picciolo, 1964, Cheal and Davis, 1974) showed that in T. trichopterus, female chemical stimuli increased reproductive and aggressive behavior in the male.

The subjects were nine male and nine female $M$. opercularis which were housed in individual 9.5-liter isolation tanks (Davis et al., 1974) for 3-5 days prior to the experiment. The females ranged from 2.8 to $4.5 \mathrm{~cm}$ in body length, the males from $4.0-5.8 \mathrm{~cm}$. Four types of stimulus fish were used consisting of male and female $M$. opercularis and $T$. trichopterus. Two individuals of each of the types of stimulus fish were kept in separate isolation tanks. An additional tank which contained no fish provided blank stimulus water. The same eight fish were used as stimuli throughout the experiment. Sheets of paper between the tanks prevented fish from seeing one another. The isolation tanks were rinsed clean at the start of the experiment and the water was continuously filtered through a small amount of activated charcoal and glass wool. Unidentified blue-green algae and bacteria grew on the walls and bottoms of tanks, and hornwort (Ceratophyllum demersum) floated in the water. Water which was removed from stimulus fish tanks was immediately replenished with fresh water from a large reservoir in the laboratory. Water temperatures ranged from $24^{\circ}$ to $26^{\circ} \mathrm{C}$ during the experiment. The fish were fed a small amount of Tetramin late in the afternoon on alternate days. Indirect natural light was augmented from $0600-2000$ hrs by Daylight fluorescent light.

The experimental tank consisted of 9.5-liter Metaframe aquarium, $30 \times 15 \times 20 \mathrm{~cm}$ high, which was arranged with its long axis toward the observer. Three of the glass walls were covered on the inside with nonmirroring, white polyvinylchloride sheets. The front wall was left clear so that the fish was in view of the observer at all times. The tank contained 8 liters of water, a layer of gravel, and a few sprigs of hornwort. An outside filter on the rear wall slowly circulated water through a thin layer of glass wool and provided background "noise" as bubbling water returned to the tank. During an experiment, fresh water flowed through the tank at a rate of $400 \mathrm{ml} / \mathrm{min}$. The water entered through a polystyrene siphon tube $(0.9 \mathrm{~cm}, \mathrm{i} . \mathrm{d}$.) in a front corner of the tank and exited through a bottom drain at the rear (Fig. 1). The 


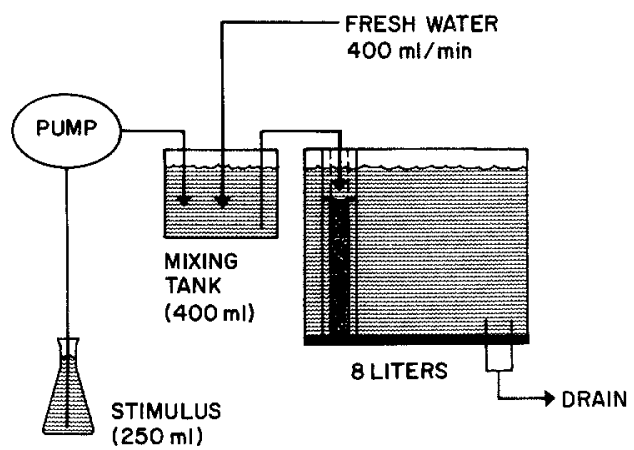

Fig. 1. Diagram of the connections between the stimulus water flask, mixing tank, and the experimental tank. The stippled area of the incurrent tube represents the channel in which the fish had access to the descending flow of water (see text).

water level in the tank was maintained by directing the drain water upward through flexible tubing to the desired elevation at which point it spilled into an open waste pipe. An $18 \mathrm{~cm}$-long tube of black polypropylene $(2.5 \mathrm{~cm}$, i.d.) was fastened vertically in the corner beneath the incurrent siphon. The uppermost $3 \mathrm{~cm}$ of the black tube extended above the surface of the water. The tube enclosed the incurrent siphon which extended $1 \mathrm{~cm}$ beneath the surface. The lowermost $10 \mathrm{~cm}$ of the black tube was hemisectioned and the front half was removed to form a vertical channel (Fig. 1). Dye showed that the channeled flow descended smoothly to the bottom and then billowed outward over the gravel. The incurrent siphon received water from a $400-\mathrm{ml}$ tank in which stimulus water was mixed with the flow of fresh water, pumped from the laboratory reservoir. A separate metering pump was used by the observer to administer stimulus water during a trial.

The subject was isolated for 3 days, then placed in the experimental tank for $1 \mathrm{hr}$ prior to administration of five trials with five different stimuli. A trial was $15 \mathrm{~min}$ long and successive trials were started at 35 -min intervals. At the start of a trial the metering pump was tumed on and fresh water was pumped into the mixing tank for $5 \mathrm{~min}$ at a rate of $50 \mathrm{ml} / \mathrm{min}$. The flow through the experimental tank was thereby increased to approximately $450 \mathrm{ml} / \mathrm{min}$. The 5 -min period was to adapt the fish to increased flow rate prior to administration of the stimulus water. The response to the fresh water flow was nil and is not further considered. Immediately after the period of fresh water flow, $250 \mathrm{ml}$ of stimulus water was administered. Each of the five stimuli: (1) male and (2) female $M$. opercularis, (3) male and (4) female $T$. trichopterus, and (5) the blank, was presented once to each subject. The order of presentation of the stimuli was varied for different subjects. The five stimulus samples were collected in clean, 250-ml Erlenmeyer flasks just prior to the first trial. The observer was unaware of the identity of the stimuli. 


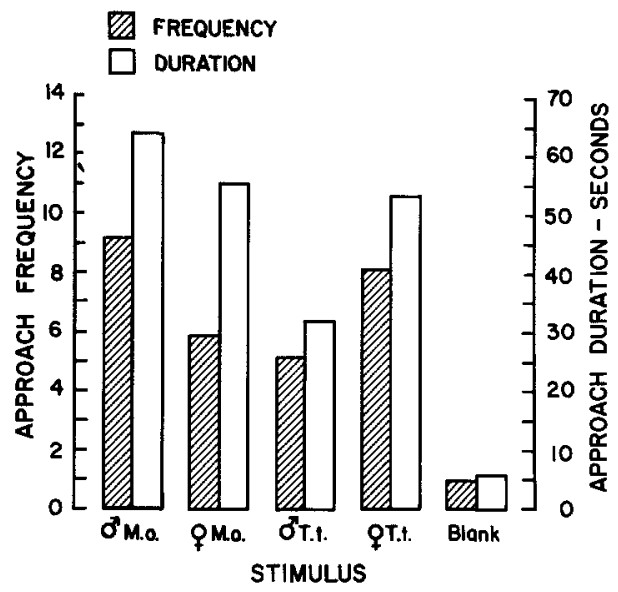

Fig. 2. The mean frequency and duration of the approach responses of $M$. opercularis to the five different kinds of stimuli.

Approaches to the channel beneath the incurrent siphon were recorded by direct observation with a manual keyboard in conjunction with an event recorder. An approach was registered when the subject placed a part of its head within the outline of the channel. Duration of approach was measured to the nearest second. Recording continued for a total of $10 \mathrm{~min}$ following the onset of pumping of the stimulus water. The recorder and the metering pump were turned off until the next trial.

In a typical approach response, the fish entered the channel near the bottom, moved upward, then withdrew. Fish occasionally swam all the way up the channel into the intact portion of the black tube and remained there for a period of seconds before backing down. The distribution of approach responses during the 10 -min period of stimulus presentation varied greatly. The first approach usually occurred 2-5 min after onset of the period.

Most of the subjects made repeated approaches to the four fish stimuli while only a few individuals, male and female, responded to the blank stimulus (Fig. 2). A 2-way ANOVA of Stimulus and Sex reveals a significant Stimulus effect on approach frequency $(F(4,64)=9.42, P<0.01)$ and duration $(F(4,64)=7.56, P<0.01)$. The Sex effect was not significant, nor was the Stimulus $\times$ Sex interaction.

The data for male and female subjects were combined for further analysis of the differences in response to the five stimuli, using paired $t$ tests. The frequency and the duration of approach were significantly greater for each of the four fish stimuli than the blank stimulus (Table 1). Significant differences in frequency or duration or in both of these response measures were obtained between the four fish stimuli except between male $M$. 
TABLE 1

Values of $t$ for the Between-Stimulus

Comparisons of Approach Frequency and Duration

\begin{tabular}{|c|c|c|}
\hline \multirow[b]{2}{*}{ Stimuli } & \multicolumn{2}{|c|}{ Response Measure } \\
\hline & Frequency & Duration \\
\hline $\begin{aligned} \text { Male } M . o . & \times \text { Female } M . o . \\
& \times \text { Male } T . t . \\
& \times \text { Female } T . t . \\
& \times \text { Blank }\end{aligned}$ & $\begin{array}{l}2.36^{*} \\
2.31^{*} \\
n s \\
3.70^{* *}\end{array}$ & $\begin{array}{c}n s \\
2.12^{*} \\
n s \\
3.78^{* *}\end{array}$ \\
\hline $\begin{aligned} \text { Female } M . o . & \times \text { Male } T . t . \\
& \times \text { Female } T . t \\
& \times \text { Blank }\end{aligned}$ & $\begin{array}{l}n s \\
-2.27^{*} \\
3.79 * * *\end{array}$ & $\begin{array}{l}2.29 * \\
n s \\
3.64 * *\end{array}$ \\
\hline $\begin{aligned} \text { Male } T . t . & \times \text { Female } T . t . \\
& \times \text { Blank }\end{aligned}$ & $\begin{array}{l}-2.28 * \\
3.64 * *\end{array}$ & $\begin{array}{l}-2.57^{*} \\
3.06^{* *}\end{array}$ \\
\hline Female $T . t . \times$ Blank & $3.83 * * *$ & $4.01 * * *$ \\
\hline
\end{tabular}

$* P<.05$

$* * P<.01$.

$* * * P<.001$.

opercularis and female $T$. trichopterus. These two stimuli resulted in significantly higher frequencies and longer durations of approach than the $M$. opercularis female and $T$. trichopterus male stimuli.

These results indicate that chemical substances which are produced by individual $M$. opercularis and $T$. trichopterus can elicit an approach response in $M$. opercularis when administered in a slow flow of fresh water. The oriented, repeated approach to the incurrent siphon suggests that the scents are attractive, rather than aversive. The possible reinforcing effects of the scents might result in conditioning the approach response to the water flow stimulus. A related factor is that a jet of fresh water can also be attractive to $M$. opercularis. The slow, diffuse flow from the incurrent channel in this experiment was only weakly attractive in the absence of chemical stimuli. The approach response may be and probably is a result of the combined effects of chemical stimuli and water flow. The differences between the response to the blank and the fish stimuli cannot be attributed solely to food particles or food scents which might be present in the $250-\mathrm{ml}$ water sample. The presence of food in the experimental tank does not appear to interfere with the approach response.

Further investigation will be needed to determine whether the effective chemical substances are common to both sexes and to both species. The response frequency data indicated that the male $M$. opercularis and female $T$. trichopterus stimuli were more attractive than the female $M$. opercularis and 
male T. trichopterus (Fig. 2). The approach-duration data showed that the male $T$. trichopterus stimulus was the least attractive of the four fish stimuli. The differences in response could indicate that the fish produced qualitatively different stimuli or different amounts of the same chemical substance. In experiments in belontid fishes of the genus Colisa (subfamily Trichogasterinae), Mainardi and Rossi (1968) and Rossi (1969) showed that chemical stimuli which are produced by females of $C$. latia or C. labiosa elicit reproductive behavior in the males of both species. Thus, the female stimuli have common effects in the males. When visual cues are present, however, the males are aroused by conspecific but not nonconspecific female chemical stimuli. Rossi (1969) stated that the results obtained in C. latia and C. labiosa also hold for $M$. opercularis. The intense arousal which can be seen in male $M$. opercularis, when they are placed in water which has previously been occupied by a female, and the approach response to a flow of water containing female stimuli are both consistent with Rossi's report. It may be emphasized, however, that females also show behavioral arousal and the approach response to male and female chemical stimuli. Our impression is that in $M$. opercularis the latency and the magnitude of the skin color changes and fin erection denoting arousal are highly variable and difficult to measure. Also color changes in females are typically less distinct than in males. The approach response is distinct and easily defined. We are investigating the reinforcing properties of male and female chemical stimuli in relation to the sex, social status, and stage of behavioral development of the individual.

\section{REFERENCES}

Cheal, M. L., and Davis, R. E. (1974). Sexual behavior: Social and ecological influences in the anabantoid fish, Trichogaster trichopterus. Behav. Biol. 10, 435-445.

Davis, R. E., Harris, C., and Shelby, J. (1974). Sex differences in aggressivity and the effects of social isolation in the anabantoid fish, Macropadus opercularis. Behav. Biol. 11, 497-509.

Forselius, S. (1957). Studies on anabantid fishes. I. II. III. Zool. Bidrag. Uppsala 32, 93-597.

Liem, K. F. (1963). "The Comparative Osteology and Phylogeny of the Anabantoiedei (Teleostei, Pisces)," p. 149. Urbana: University of Illinois Press.

Mainardi, D., and Rossi, A. C. (1968). Communicazoine chimica in rapporto alla costruzione del nido nel pesce Anabantide Colisa lalia. Rc. Ist. lomb. Sci. Lett. (B), $102,23-28$.

Picciolo, A. R. (1964). Sexual and nest discrimination in anabatid fishes of the genera Colisa and Trichogaster. Ecol. Monogr. 34, 53-57.

Regan, C. T. (1906). The asiatic fishes of the family Anabantidae. Proc. Zool. Soc. London 767-787.

Rossi, A. C. (1969). Chemical signals and nest building in two species of Colisa (Pisces, Anabantidae). Monitore Zool. Ital. (N.S.) 3, 225-237.

Ward, R. W. (1967). Ethology of the paradise fish, Macropodus opercularis I. Differences between domestic and wild fish. Copeia 4, 809-813. 